\title{
Angioplasty for dysfunctional arteriovenous fistulas: a meta- analysis of recent randomized controlled trials compared paclitaxel-coated balloon versus conventional balloon angioplasty
}

Qin Yang

Chengdu Third People's Hospital

Yi Zhou

Cardionovum Co, Ltd

Kui Cai

Cardionovum Co, Ltd

Yufang Chen

Cardionovum Co, Ltd

Congying Xia ( $\nabla$ congy.xia@wchscu.cn)

Sichuan University West China Hospital https://orcid.org/0000-0003-4304-5965

Research article

Keywords: Arteriovenous fistula, Drug-coated balloon, Hemodialysis vascular access, Meta-analysis

Posted Date: July 26th, 2021

DOI: https://doi.org/10.21203/rs.3.rs-748410/v1

License: (9) (1) This work is licensed under a Creative Commons Attribution 4.0 International License. Read Full License 


\section{Abstract \\ Background}

Stenosis in arteriovenous fistulas (AVF) due to neointimal hyperplasia is one of the most common causes of hemodialysis vascular access dysfunction. Treating patients with dysfunctional AVF with drug-coated balloon (DCB) angioplasty may potentially improve outcomes. This systematic review aimed to compare the effectiveness and safety of DCB angioplasty versus conventional balloon angioplasty by pooling evidence from the most recent randomized controlled trials.

\section{Methods}

We conducted a comprehensive literature search in the Medline, Embase, and Cochrane central databases. Two independent researchers screened the article, extracted interest and evaluated included studies for risk of bias. Pooled estimation was conducted in terms of 6-month target-lesion primary patency (TLPP) and target-lesion reintervention (TLR), as well as other outcomes. Results were expressed with odds ratio (OR) and 95\% confidence interval (Cl).

\section{Results}

A total of 4 RCTs were identified and included in the meta-analyses, with 911 participants. There was no significant increase in rates of 6 -month TLPP $(\mathrm{OR} 1.63,95 \% \mathrm{Cl} 0.39-6.79, \mathrm{p}=0.35)$, or decrease in 6-month TLR (OR 0.45, 95\% $\mathrm{Cl} 0.17-1.19 \mathrm{p}=0.07)$ in patients who received DCB as compared to those who received conventional balloon angioplasty. Similarly, we found no difference in the 6-month access circuit primary patency and reinvention between the two groups.

\section{Conclusion}

There was no evidence supporting that DCB has a statistically significant higher rate of TLPP and lower rates of TLR in the treatment of dysfunctional AVF than conventional balloon angioplasty. However, DCB was non-inferior to conventional balloon angioplasty in terms of safety. Therefore, further study is needed to clarify whether DCB angioplasty can benefit hemodialysis patients with dysfunction AVF.

\section{Introduction}

Hemodialysis is the most typical renal replacement modality for end-stage renal disease (ESRD) patients, and arteriovenous fistulas (AVF) have been recommended as the optimal modality of vascular access (1). Nonetheless, its vascular access dysfunction contributed most to patients' mortality and hospitalization $(1,2)$. Stenosis in AVF due to neointimal hyperplasia is one of the most common causes of hemodialysis vascular access dysfunction (3). Percutaneous transluminal angioplasty with a conventional plain balloon is a routine therapy for stenosis in AVF; however, its durability is a significant concern and repeated intervention is constantly needed. It has been reported in some small studies that the use of drug-coated balloons (DCB) with a layer of antiproliferative drug paclitaxel may have the potential to improve outcomes. In contrast, other studies reported a contradictory result (4-10).

Several randomized controlled trials (RCTs) that compared DCB angioplasty with conventional balloon angioplasty for the treatment of dysfunctional hemodialysis vascular access with a larger sample size have been published (11-14). Results of these trials were less consistent and led to an ongoing debate on whether DCB angioplasty could indeed improve outcomes. Unfortunately, there is no updated meta-analysis regarding this topic. Therefore, we designed this comprehensive systematic review and meta-analysis of most recent RCTs to evaluate whether DCB angioplasty for the treatment of dysfunctional hemodialysis vascular access is potentially beneficial compared to conventional balloon angioplasty. In addition, the effectiveness and safety endpoints of the DCB angioplasty against traditional angioplasty of the balloon were assessed. 


\section{Methods}

According to Cochrane's Collaboration recommendations and Preferred Reporting Items for Systematic Reviews and Metaanalysis (PRISMA) statement (15), we followed the PRISMA checklist, which can be found in the supplements.

\section{Study selection and data extraction}

A comprehensive literature search in the Medline, Embase and Cochrane central databases was conducted from inception to 2021 April. The detailed search syntax is presented in table S1. We restricted the studies to human trials. Additional literature were manually searched by screening relevant references. Studies that meet all the following criteria were included: (1) in hemodialysis patients with dysfunctional AVF, (2) with a randomized controlled design, (3) a comparison between DCB angioplasty and conventional balloon angioplasty, (4) a sample size of at least 50 patients per group. A study was excluded if: (1) results were not published in a peer-viewed journal or data of interest was not available, (2) was not published in English or Chinese, (3) enrolled patients was partly with arteriovenous graft, (4) did not report outcomes of interest. The primary clinical outcome of interest was target lesion primary patency (TLPP) six months after the indexed procedure. We also assessed secondary endpoints, including clinically-driven target lesion revascularization (TLR), access circuit primary patency, access circuit reintervention, severe adverse events and all-cause mortality. In the case of the multiple publications of the same trial, we included the one with a longer follow-up.

Two independent researchers (Y.Z and Q.Y) first screened the title and abstracted it to identify relevant literatures and then viewed the entire manuscript to check if a study met the predefined selection criteria. Next, the study setting, sample size, clinical characteristics, interventional procedures, follow-up periods and clinical outcomes were extracted from eligible RCTs using predesigned data extraction forms.

The quality and risk of bias of each selected trial were assessed independently by two researchers (Y.Z and Q.Y) using the assessment tool recommended by the Cochrane Collaboration (16). Discrepancies between two researchers were discussed with a third researcher (C.X) and solved by reaching a consensus.

\section{Statistical analyses}

The primary outcome, i.e., pooled estimation of an effect size of 6-month TLPP and other outcomes, was expressed with odds ratio (OR) and $95 \%$ confidence interval $(\mathrm{Cl})$. Mantel-Haenszel methods with a random-effects model were used for pooling analyses accounted for the dichotomous outcomes and inter-study heterogeneity. Heterogeneity across included studies was assessed using Cochran's Q test and $\mathrm{I}^{2}$ statistics. A p-value lower than 0.1 or $\mathrm{I}^{2}$ statistic above $50 \%$ indicates heterogeneity among included studies. A visual judgment of funnel plots assessed publication bias (or small-study effect) for symmetry. We also performed a sensitivity analysis using the leave-one-out method. All statistical analyses were performed using $\mathrm{R}$ (version 4.0) with the 'meta' and 'dmetar' package $(17,18)$.

\section{Results}

\section{Included studies}

A total of 4 RCTs were identified and included in the meta-analyses, with 956 participants (11-14). An overview of the study flow of the selection process is presented in Fig. 1. The study design of the identified trials and clinical characteristics of included patients are shown in Tables 1 and 2. All trials had a multicenter design and a relatively large sample size. Enrolled patients in the trial conducted by Yin et al. were younger than in the other three trials. Moreover, in their study, the study population had fewer complications, including a history of stroke, coronary artery disease and peripheral vascular disease. 
Table 1

Design of included trials

\begin{tabular}{|c|c|c|c|c|c|c|c|}
\hline Study & $\begin{array}{l}\text { Number } \\
\text { (DCB: } \\
\text { PB) }\end{array}$ & $\begin{array}{l}\text { Number } \\
\text { of } \\
\text { Centers }\end{array}$ & Region & Type of DCB & $\begin{array}{l}\text { Enrolment } \\
\text { Time } \\
\text { (year) }\end{array}$ & $\begin{array}{l}\text { Primary } \\
\text { Endpoint }\end{array}$ & $\begin{array}{l}\text { Maximum Available } \\
\text { Follow-up (months) }\end{array}$ \\
\hline $\begin{array}{l}\text { Trerotola, } \\
2020\end{array}$ & $141: 144$ & 23 & US & Lutonix, Bard & $\begin{array}{l}2015.6- \\
2016.3\end{array}$ & $\begin{array}{l}\text { TLPP at } 6 \\
\text { mo. }\end{array}$ & 24 \\
\hline $\begin{array}{l}\text { Lookstein, } \\
2020\end{array}$ & $170: 160$ & 29 & $\begin{array}{l}\text { US, Japan, and } \\
\text { New Zealand }\end{array}$ & $\begin{array}{l}\text { IN.PACT, } \\
\text { Medtronic }\end{array}$ & $\mathrm{N} / \mathrm{A}$ & $\begin{array}{l}\text { TLPP } \\
\text { over } 6 \\
\text { mo. }\end{array}$ & 12 \\
\hline $\begin{array}{l}\text { Karunanithy, } \\
2021\end{array}$ & 106:106 & 20 & UK & Lutonix, Bard & $\begin{array}{l}2015.11- \\
2018.10\end{array}$ & $\begin{array}{l}\text { Time to } \\
\text { loss of } \\
\text { TLPP }\end{array}$ & 12 \\
\hline Yin, 2021 & $78: 83$ & 10 & China & $\begin{array}{l}\text { Aperto, } \\
\text { Cardionovum }\end{array}$ & $\begin{array}{l}2016.11- \\
2017.7\end{array}$ & $\begin{array}{l}\text { TLPP at } 6 \\
\text { mo. }\end{array}$ & 12 \\
\hline
\end{tabular}

Table 2

Basic clinical characteristics of included trials

\begin{tabular}{|c|c|c|c|c|c|c|c|c|c|}
\hline Study & $\begin{array}{l}\text { Mean } \\
\text { Age } \\
\text { (DCB: } \\
\text { PB) }\end{array}$ & $\begin{array}{l}\text { Male (\%) } \\
\text { (DCB: PB) }\end{array}$ & $\begin{array}{l}\text { DM (n) } \\
\text { (DCB: } \\
\text { PB) }\end{array}$ & $\begin{array}{l}\text { Smokers } \\
\text { (n) } \\
\text { (DCB: } \\
\text { PB) }\end{array}$ & $\begin{array}{l}\text { Hypertension } \\
\text { (n) (DCB: } \\
\text { PB) }\end{array}$ & $\begin{array}{l}\text { Hyperlipidemia } \\
\text { (n) (DCB: PB) }\end{array}$ & $\begin{array}{l}\text { PVD } \\
\text { (n) } \\
\text { (DCB: } \\
\text { PB) }\end{array}$ & $\begin{array}{l}\text { CAD } \\
\text { (n) } \\
\text { (DCB: } \\
\text { PB) }\end{array}$ & $\begin{array}{l}\text { Stroke } \\
\text { (n) } \\
\text { (DCB: } \\
\text { PB) }\end{array}$ \\
\hline $\begin{array}{l}\text { Trerotola, } \\
2020\end{array}$ & $\begin{array}{l}64 \pm \\
15: \\
61 \pm \\
13\end{array}$ & $62 \%: 59 \%$ & $82: 94$ & $64: 66$ & $133: 142$ & $85: 84$ & $14: 26$ & $43: 40$ & $18: 13$ \\
\hline $\begin{array}{l}\text { Lookstein, } \\
2020\end{array}$ & $\begin{array}{l}65.8 \\
\pm \\
13.1: \\
65.5 \\
\pm \\
13.4\end{array}$ & $65.9 \%: 63.1 \%$ & $107: 110$ & $83: 71$ & $155: 151$ & $92: 84$ & $33: 24$ & $7: 14$ & NR \\
\hline $\begin{array}{l}\text { Karunanithy, } \\
2021\end{array}$ & $\begin{array}{l}66.9 \\
\pm \\
12.7: \\
64.1 \\
\pm \\
13.3\end{array}$ & $63.2 \%: 57.5 \%$ & $58: 46$ & $49: 49$ & NR & NR & $13: 18$ & $25: 30$ & NR \\
\hline Yin, 2021 & $\begin{array}{l}56 \pm \\
13: \\
54 \pm \\
13\end{array}$ & $56 \%: 51 \%$ & $27: 29$ & $24: 21$ & $66: 70$ & $9: 17$ & $1: 0$ & $7: 0$ & $2: 8$ \\
\hline
\end{tabular}

\section{Risk-of-bias assessment}

Several domains, including selection, performance, detection, attrition and reporting bias, were assessed for included trials. The quality of each included trials is presented in Fig. 2. In general, all trials were well performed according to predefined study protocols to minimize bias.

\section{Primary clinical outcomes}


As present in Fig. 3A, half of the included trials provided evidence supporting that DCB angioplasty had higher rates of 6-month TLPP compared to conventional balloon angioplasty. In the pooling analyses, there was no significant increase in rates of 6month TLPP in patients who received DCB as compared to those who were allocated to the conventional balloon angioplasty group (OR 1.63, 95\% Cl 0.39-6.79, $p=0.35$ ). The events rate of 6-month TLR was only reported in three trials. Similarly, we found no significant difference in 6-month TLR between DCB and conventional balloon angioplasty $(\mathrm{OR} 0.45,95 \% \mathrm{Cl} 0.17-1.19 \mathrm{p}=$ 0.07, Fig. 3B).

\section{Other outcomes}

We also assessed access circuit primary patency at 6 months, as present in Fig. 4A. Patients who received DCB were not found to have a higher rate of access circuit primary patency at 6 months than those who received conventional balloon angioplasty (OR 1.41, 95\% $\mathrm{Cl} 0.52-3.85, \mathrm{p}=0.36$ ). Access circuit reintervention rate within 6 months was reported in three studies. In the pooled analysis, event rates of 6-month access circuit reintervention were not significantly lower in the DCB group (Fig. 4B).

Safety endpoint regarding severe adverse events within 30 days was reported in half of the included trials. Lookstein et al. and Trerotola et al. reported that severe adverse event rate within 30 days for DCB was significantly non-inferior than conventional balloon angioplasty. Yin et al. found no difference in the 12-month severe adverse event rate between DCB and conventional balloon angioplasty. Similarly, in the trial conducted by Trerotola et al., no difference in severe adverse event rate was found between the two groups through the entire trial up to a maximum available follow-up of 2 years.

\section{Publication bias and Sensitivity analysis}

Visual inspection of funnel plots revealed a likely asymmetric distribution among included trials regarding all outcomes of interest, indicating a potential publication bias due to a small study effect (figure S1A-D). The contribution of each trial to the overall heterogeneity is also presented by the Baujat plot (figure S2A-D). $I^{2}$ statistic revealed considerable heterogeneities for analyses of TLPP, TLR, access circuit primary patency and reintervention at 6 months (Fig. 3,4).

We further conducted a sensitivity analysis to evaluate whether an individual trial strongly drove the results by removing a single trial at one time. We found the trial conducted by Karunanithy et al. contributed mostly to the overall heterogeneity regarding 6month TLPP. After removing this trial, the pooled estimate of the effect size of 6-month TLPP increased to be 2.83 but remained statistically insignificant (figure S3A). In the case of 6-month access circuit primary patency and reintervention, the study of Lookstein et al. contributed mostly to the overall heterogeneity. After removing this trial, inter-study heterogeneity reduced substantially to zero.

\section{Discussion}

The main findings of our study include: (1) 6-month TLPP rate in dysfunction hemodialysis AVF patients who received DCB was higher than those who were treated with conventional balloon angioplasty; however, this was not statistically significant; (2) there was no evidence supporting that DCB had a significantly lower rate of 6-month TLR; (3) there was no significant difference in terms of access circuit primary patency, access circuit reintervention, or severe adverse events between DCB and conventional balloon angioplasty; (4) substantial inter-heterogeneity among included trials were observed.

This meta-analysis failed to provide evidence supporting that DCB has a statistically significant higher rate of TLPP and lower rates of TLR, as compared to conventional balloon angioplasty within 6 months after the indexed procedure; however, a trend was observed. The study of Trerotola et al. and Lookstein had a significant influence on the pooled estimate of effect. Notably, Trerotola et al. reported an unlike the benefit of DCB for the treatment of dysfunctional AVF compared to conventional balloon angioplasty. In contrast, Lookstein et al. advocated that DCB angioplasty was superior to conventional balloon angioplasty and was non-inferior in terms of adverse events. Substantial heterogeneity was observed among included studies. This heterogeneity may be explained by included trials that used the different brands of DCB devices. In the study of Trerotola et al., the Lutonix balloon with a paclitaxel load of $2 \mu \mathrm{g} / \mathrm{mm}^{2}$ was used, while in the study of Lookstein, the IN.PACT balloon carrying a paclitaxel dose of $3.5 \mu \mathrm{g} / \mathrm{mm}^{2}$ was used. Besides drug dose density, excipients are critical components of the DCB (19). In the study of 
Yin et al., the APERTO DCB with a coating excipient of ammonium salt was used. While coating excipient of Lutonix and IN.PACT was polysorbate-sorbitol and urea, respectively. All these perspectives as mentioned above may lead to a difference in the amount of drug delivered to the target lesion and its efficacy and safety. However, clear evidence in animal experiments of AVF is scarce.

This meta-analysis is different from prior meta-analyses in the following perspectives (20-22): (1) we only included RCTs with generally high quality and relatively larger sample size, which have higher evidence level than observational studies; (2) RCTs included in our study were up to date; (3) we excluded patients who had arteriovenous graft and focused only on AVF. Nevertheless, in the study of Kennedy et al. and Wee et al., retrospective studies and prospective cohorts were included $(21,22)$. In the study of Liao et al., RCTs with a small sample size and inconclusive results were included, which are likely to be susceptible to publication bias and may, therefore, be less reliable (20).

The limitation of this systematic review and meta-analyses needs to be addressed. First, the overall heterogeneity and risk-ofbias observed in our meta-analysis were attributed to each included original RCT. However, individual-level data are needed to explore the potential cause of heterogeneity fully, however, they were not available for us. Second, publication bias or smallstudy effect was inspected visually using a funnel plot. Due to the limited number of RCTs, a statistical test for the funnel plot asymmetry was not performed. Third, our pooled results in terms of TLPP should be interpreted with an awareness that in the trial conducted by Yin et al., the definition of TLPP was different from the other three studies, which included a peak systolic velocity ratio lower or equal to 2.0 as determined using doppler ultrasound. Fourth, it is only feasible for us to assess the effectiveness of DCB in terms of the short-term outcomes, i.e. within 6 months after the indexed procedure, long-term outcomes regarding the efficacy and safety wait for longer follow-up results.

In conclusion, we failed to provide evidence supporting that DCB has a statistically significant higher rate of TLPP or lower rates of TLR in the treatment of dysfunctional AVF than conventional balloon angioplasty within 6 months after the indexed procedure. However, DCB was non-inferior to conventional balloon angioplasty in terms of safety. Therefore, further study is needed to clarify whether DCB angioplasty can benefit hemodialysis patients with dysfunction AVF.

\section{Declarations}

\section{Funding}

None.

Conflict of interest: $\mathrm{YZ}, \mathrm{KC}$, and $\mathrm{YC}$ are employed by the Cardionovum Co, Ltd, Wuhan China. Other authors declare that the research was conducted in the absence of any commercial or financial relationships that could be construed as a potential conflict of interest.

\section{Author contributions:}

Conception and design: Yufang Chen, Qin Yang, Congying Xia; Administrative support: Yufang Chen; Provision of study materials: Yi Zhou; Collection and assembly of data: Congying Xia, Qin Yang and Yi Zhou; Data analysis and interpretation: Congying Xia, Qin Yang and Yi Zhou; Manuscript writing: All authors; Final approval of manuscript: All authors.

\section{References}

1. Lok CE, Huber TS, Lee T, et al. KDOQI Clinical Practice Guideline for Vascular Access: 2019 Update. Am J Kidney Dis. 2020;75:1-s164.

2. Bittl JA. Catheter interventions for hemodialysis fistulas and grafts. JACC Cardiovasc Interv. 2010;3:1-11.

3. Roy-Chaudhury P, Arend L, Zhang J, et al. Neointimal hyperplasia in early arteriovenous fistula failure. Am J Kidney Dis. 2007;50:782-90. 
4. Karmota AG. Paclitaxel coated-balloon (PCB) versus standard plain old balloon (POB) fistuloplasty for failing dialysis access. Ann R Coll Surg Engl. 2020;102:601-5.

5. Kitrou PM, Katsanos K, Spiliopoulos S, et al. Drug-eluting versus plain balloon angioplasty for the treatment of failing dialysis access: final results and cost-effectiveness analysis from a prospective randomized controlled trial (NCT01174472). Eur J Radiol. 2015;84:418-23.

6. Maleux G, Vander Mijnsbrugge W, Henroteaux D, et al. Multicenter, Randomized Trial of Conventional Balloon Angioplasty versus Paclitaxel-Coated Balloon Angioplasty for the Treatment of Dysfunctioning Autologous Dialysis Fistulae. J Vasc Interv Radiol. 2018;29:470-5.e3.

7. Lai CC, Fang HC, Tseng CJ, et al. Percutaneous angioplasty using a paclitaxel-coated balloon improves target lesion restenosis on inflow lesions of autogenous radiocephalic fistulas: a pilot study. J Vasc Interv Radiol. 2014;25:535-41.

8. Patanè D, Giuffrida S, Morale W, et al. Drug-eluting balloon for the treatment of failing hemodialytic radiocephalic arteriovenous fistulas: our experience in the treatment of juxta-anastomotic stenoses. J Vasc Access. 2014;15:338-43.

9. Björkman P, Weselius EM, Kokkonen T, et al. Drug-Coated Versus Plain Balloon Angioplasty In Arteriovenous Fistulas: A Randomized, Controlled Study With 1-Year Follow-Up (The Drecorest li-Study). Scand J Surg. 2019;108:61-6.

10. Roosen LJKY, Vos JA, de Jong GM, Bos WJ, Elgersma OE. Paclitaxel-coated balloons do not prevent recurrent stenosis in hemodialysis access fistulae: results of a randomized clinical trial. Ital J Vasc Endovasc Surg. 2017;24:35-40.

11. Yin Y, Shi Y, Cui T, et al. Efficacy and Safety of Paclitaxel-Coated Balloon Angioplasty for Dysfunctional Arteriovenous Fistulas: A Multicenter Randomized Controlled Trial. Am J Kidney Dis 2021.

12. Trerotola SO, Saad TF, Roy-Chaudhury P. The Lutonix AV Randomized Trial of Paclitaxel-Coated Balloons in Arteriovenous Fistula Stenosis: 2-Year Results and Subgroup Analysis. J Vasc Interv Radiol. 2020;31:1-14.e5.

13. Karunanithy N, Robinson EJ, Ahmad F, et al. A multicenter randomized controlled trial indicates that paclitaxel-coated balloons provide no benefit for arteriovenous fistulas. Kidney Int 2021.

14. Lookstein RA, Haruguchi H, Ouriel K, et al. Drug-Coated Balloons for Dysfunctional Dialysis Arteriovenous Fistulas. N Engl J Med. 2020;383:733-42.

15. Page MJ, McKenzie JE, Bossuyt PM, et al. The PRISMA 2020 statement: an updated guideline for reporting systematic reviews. BMJ. 2021;372:n71.

16. Higgins JPT, Altman DG, Gøtzsche PC, et al. The Cochrane Collaboration's tool for assessing risk of bias in randomised trials. 2011;343:d5928.

17. Balduzzi S, Rücker G, Schwarzer G. How to perform a meta-analysis with R: a practical tutorial. Evid Based Ment Health. 2019;22:153-60.

18. Harrer M, Cuijpers P, Furukawa TA, et al. Doing Meta-Analysis With R: A Hands-On Guide. 1st ed. Boca Raton: Chapman \& Hall/CRC Press; 2021.

19. Radke PW, Joner M, Joost A, et al. Vascular effects of paclitaxel following drug-eluting balloon angioplasty in a porcine coronary model: the importance of excipients. Eurolntervention. 2011;7:730-7.

20. Liao MT, Chen MK, Hsieh MY, et al. Drug-coated balloon versus conventional balloon angioplasty of hemodialysis arteriovenous fistula or graft: A systematic review and meta-analysis of randomized controlled trials. PLoS One. 2020;15:e0231463.

21. Kennedy SA, Mafeld S, Baerlocher MO, et al. Drug-Coated Balloon Angioplasty in Hemodialysis Circuits: A Systematic Review and Meta-Analysis. J Vasc Interv Radiol 2019;30:483 - 94.e1.

22. Yan Wee IJ, Yap HY, Hsien Ts'ung LT, et al. A systematic review and meta-analysis of drug-coated balloon versus conventional balloon angioplasty for dialysis access stenosis. J Vasc Surg 2019;70:970-9.e3.

\section{Figures}




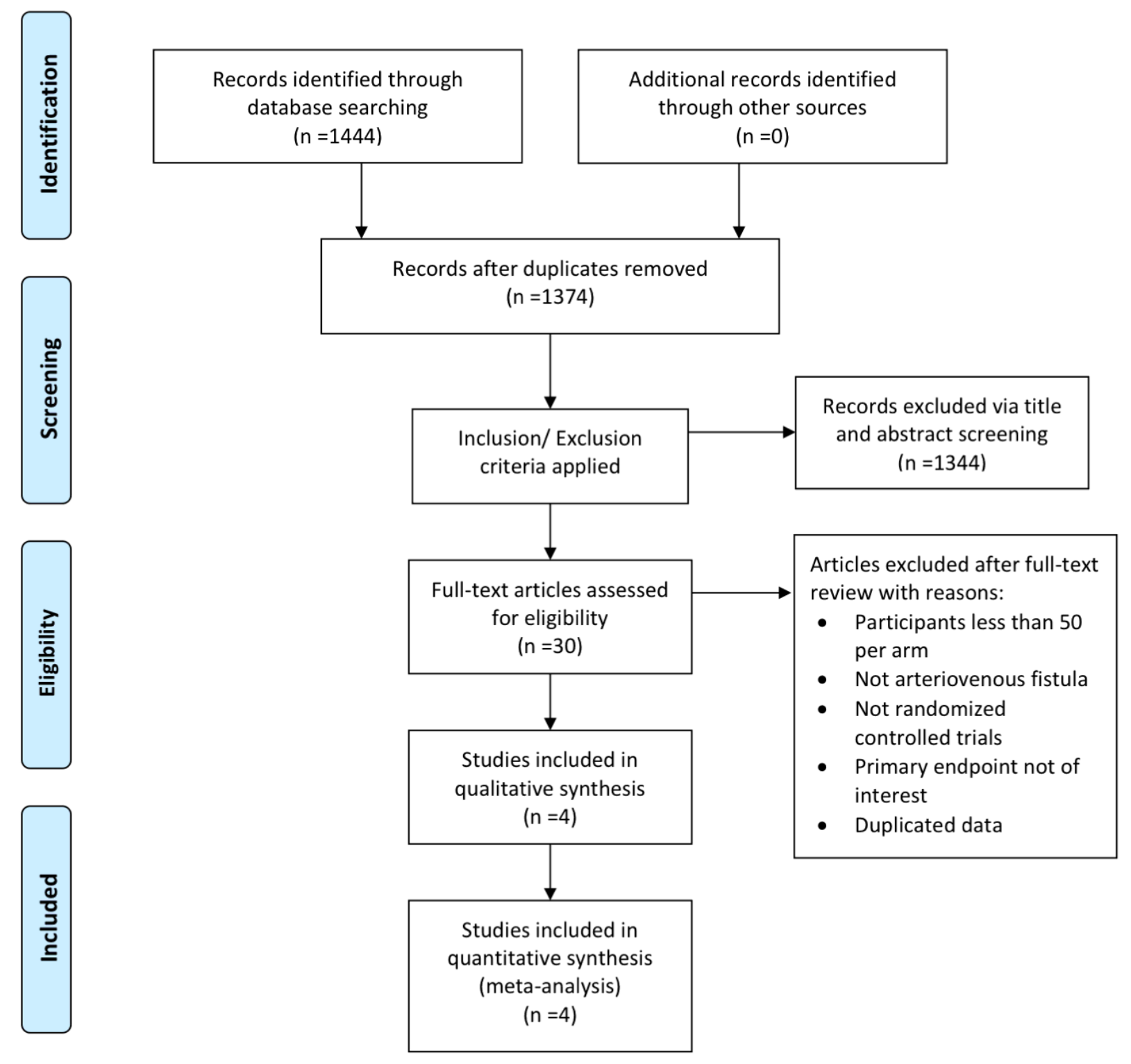

Figure 1

The flow of study selection process. 

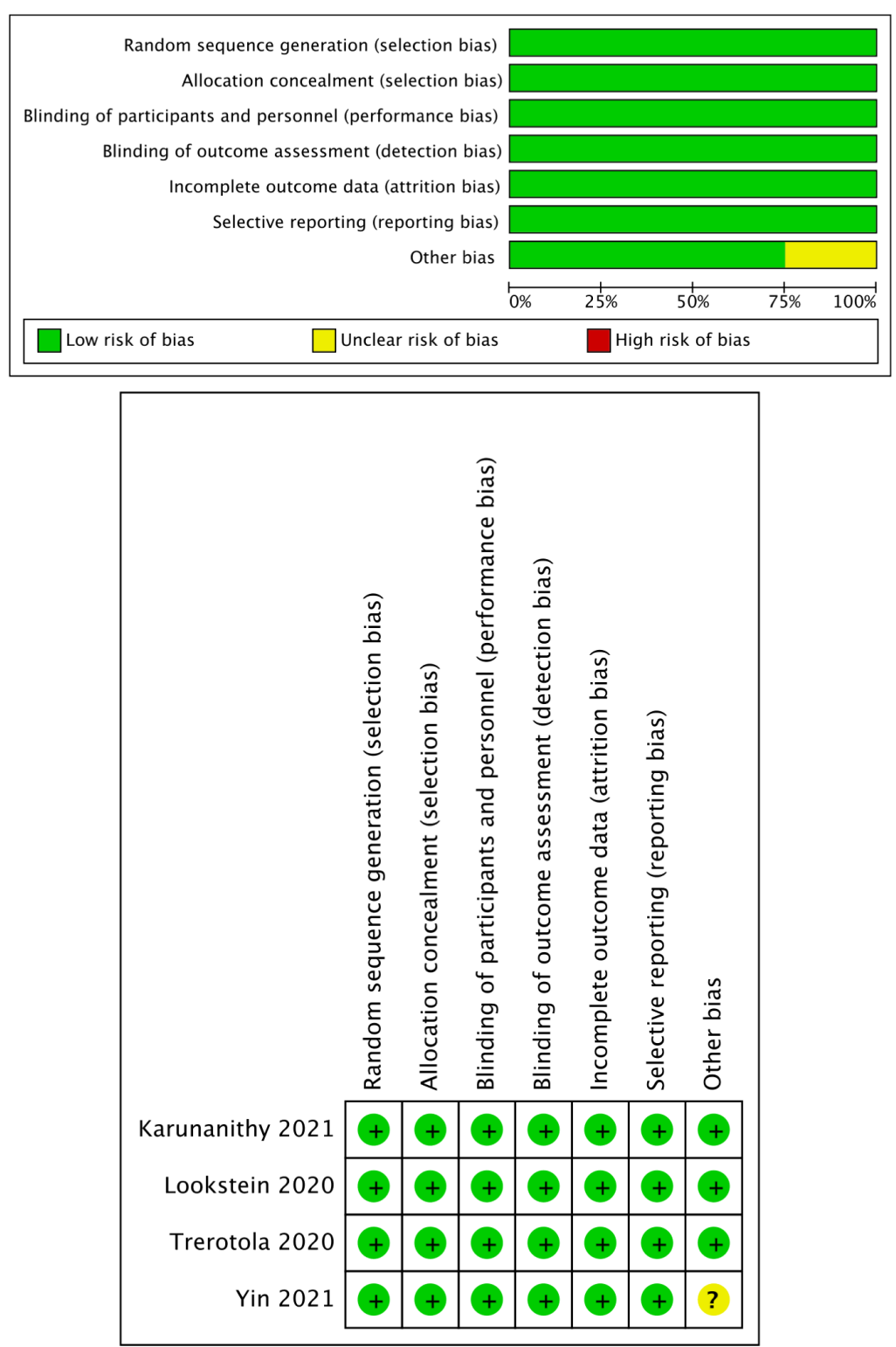

\section{Figure 2}

Risk of bias graph (upper) and summary (lower) for included trials. 


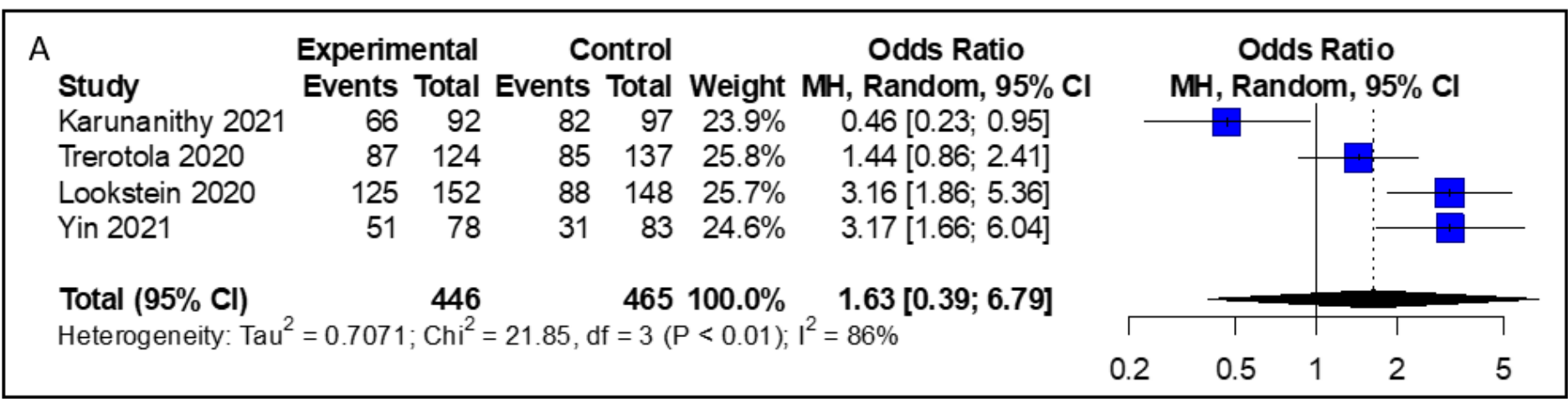

B

\begin{tabular}{|c|c|c|c|c|c|c|}
\hline \multirow{5}{*}{$\begin{array}{l}\text { Study } \\
\text { Lookstein } 2020 \\
\text { Trerotola } 2020 \\
\text { Yin } 2021\end{array}$} & \multicolumn{2}{|c|}{ Experimental } & \multicolumn{2}{|c|}{ Control } & \multicolumn{2}{|c|}{ Odds Ratio } \\
\hline & Events & Total & Events & Total & Weight & MH, Random, 95\% \\
\hline & 25 & 152 & 59 & 148 & $37.0 \%$ & $0.30[0.17 ; 0.51]$ \\
\hline & 44 & 141 & 64 & 144 & $41.5 \%$ & $0.57[0.35 ; 0.92]$ \\
\hline & 11 & 78 & 18 & 83 & $21.4 \%$ & $0.59[0.26 ; 1.35]$ \\
\hline I) & & 371 & & 37 & $00.0 \%$ & $0.45[0.17 ; 1.19]$ \\
\hline
\end{tabular}

Odds Ratio Odds Ratio

Heterogeneity: Tau $^{2}=0.0623 ; \mathrm{Chi}^{2}=3.58, \mathrm{df}=2(\mathrm{P}=0.17) ; \mathrm{I}^{2}=44 \%$

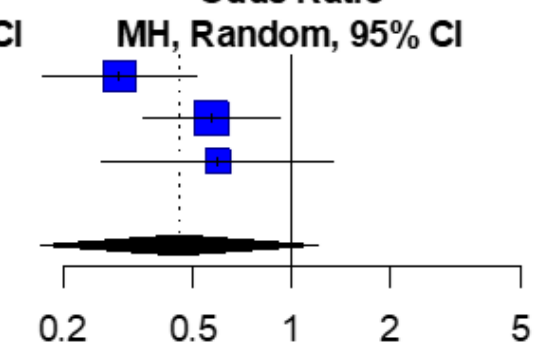

Figure 3

Forrest plot of 6-month target-lesion primary patency $(\mathrm{A})$ and 6-month target-lesion reintervention $(\mathrm{B})$ in the drug-coated balloon (experimental) and conventional plain balloon (control).

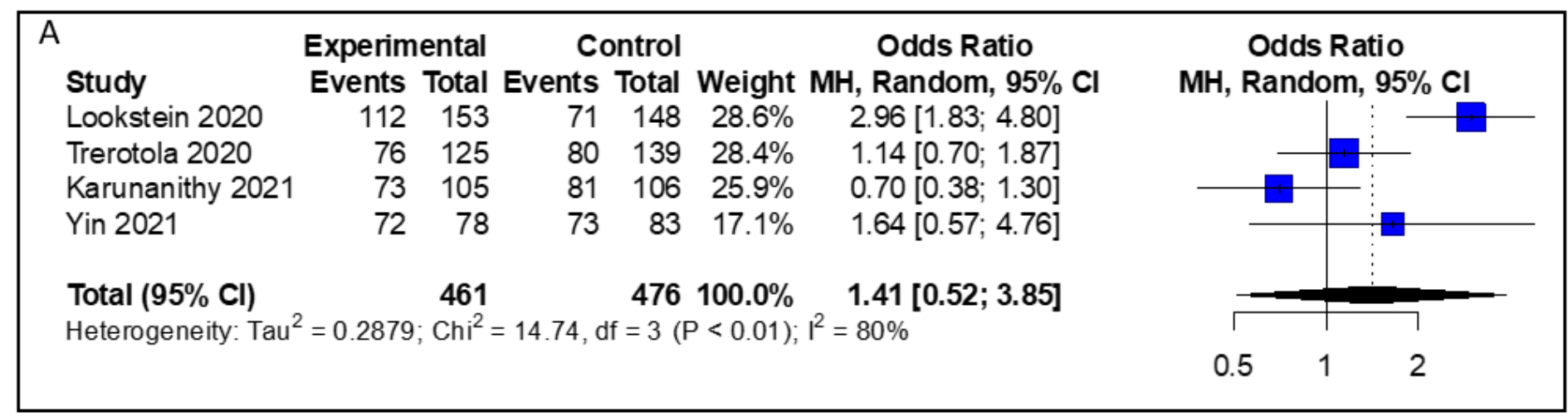

B

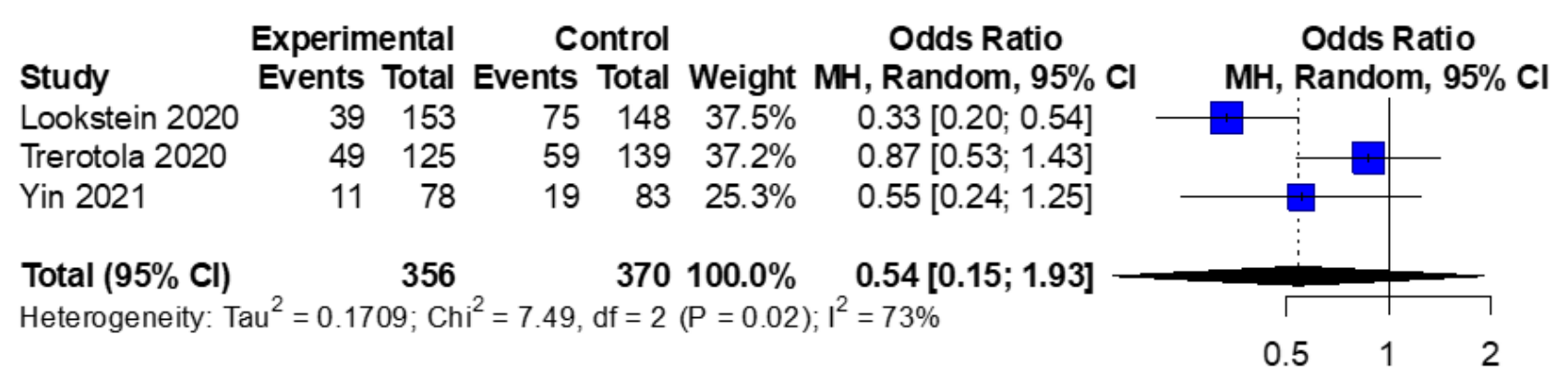

Figure 4

Forrest plot of 6-month access circuit primary patency (A) and 6-month access circuit reintervention (B) in the drug-coated balloon (experimental) and conventional plain balloon (control). 


\section{Supplementary Files}

This is a list of supplementary files associated with this preprint. Click to download.

- supplements.docx 